\title{
Studi Semiotika Makna Upacara Perayaan Dewi Kwan Im di Kelenteng Dewi Kwan Im Palembang
}

\author{
Jessica Gunawan, Suzy Azeharie \\ jessicagunawan01@gmail.com, suzya@fikom.untar.ac.id
}

Fakultas Ilmu Komunikasi Universitas Tarumanagara

\begin{abstract}
This research discusses of rituals for Dewi Kwan Im celebration that is the day Dewi Kwan Im leaving the world. Dewi Kwan Im is the Goddess who was highly respected by Khonghucu people's because Dewi Kwan Im trusted can be helps Khonghucu people's who need helps. Therefore Khonghucu people's always celebrate the biggest day of Dewi Kwan Im. Dewi Kwan Im Temple where located at KM 12 Palembang also held a celebration ceremony in welcoming the great day of Dewi Kwan Im with has its own rituals tradition in carrying out the celebration ceremony of Dewi Kwan Im. Every rituals procession which help held in Dewi Kwan Im Palembang Temple has a meaning in it. The purpose of this research is to know the meaning of rituals celebration for Dewi Kwan Im at Dewi Kwan Im Temple Palembang and to know the tradition which did by the Khonghucu people's at Dewi Kwan Im Temple Palembang in celebrating the rituals of Dewi Kwan Im. The theories which used in this research are semiotics theory, transcendental communication theory and assimilation theory. The research methods that used is qualitative research methods with a case study approach. The data results were obtained through direct observation to Dewi Kwan Im Palembang Temple, interviews with five sources, and literature studies. The conclusion of this research is the celebration rituals of Dewi Kwan Im at Dewi Kwan Im Palembang Temple is a form of respect and gratitude of Khonghucu people's to Dewi Kwan Im for the blessings and help which recieved by the Khonghucu people's during this time. Other than that the tradition which there at Dewi Kwan Im Palembang Temple is a combination of Hokkien culture society.
\end{abstract}

Keywords: Celebration Rituals of Dewi Kwan Im, Dewi Kwan Im Palembang Temple, Khonghucu People's, Meaning, Tradition

\begin{abstract}
Abstrak
Penelitian ini membahas upacara perayaan Dewi Kwan Im yaitu hari Dewi Kwan Im meninggalkan dunia. Dewi Kwan Im merupakan dewi yang sangat dihormati oleh umat Khonghucu sebab Dewi Kwan Im dipercaya dapat membantu umat Khonghucu yang membutuhkan pertolongan. Oleh karena itu umat Khonghucu selalu merayakan hari besar Dewi Kwan Im. Kelenteng Dewi Kwan Im yang berada di KM 12 Palembang turut mengadakan upacara perayaan dengan memiliki tradisi sendiri dalam melaksanakan upacara perayaan Dewi Kwan Im. Setiap prosesi upacara yang dilaksanakan di Kelenteng Dewi Kwan Im Palembang mempunyai makna di dalamnya. Tujuan penelitian ini adalah untuk mengetahui makna upacara perayaan Dewi Kwan Im yang dilaksanakan di Kelenteng Dewi Kwan Im Palembang dan untuk mengetahui tradisi yang dilakukan oleh umat Khonghucu di Kelenteng Dewi Kwan Im Palembang dalam merayakan upacara Dewi Kwan Im. Teori yang digunakan dalam penelitian ini yaitu teori semiotika, komunikasi transendental dan asimilasi. Metode penelitian yang digunakan adalah metode penelitian kualitatif dengan pendekatan studi kasus. Hasil data diperoleh melalui observasi langsung ke Kelenteng Dewi Kwan Im Palembang, wawancara dengan lima narasumber, dan studi kepustakaan. Kesimpulan dari penelitian ini adalah upacara perayaan Dewi Kwan Im yang dilaksanakan di Kelenteng Dewi
\end{abstract}


Kwan Im Palembang merupakan bentuk rasa hormat dan terima kasih umat Khonghucu kepada Dewi Kwan Im atas berkat dan pertolongan yang diterima oleh umat Khonghucu selama ini. Selain itu tradisi yang ada di Kelenteng Dewi Kwan Im Palembang merupakan gabungan dari budaya masyarakat Hokkien.

Kata Kunci: Kelenteng Dewi Kwan Im Palembang, Makna, Tradisi, Umat Khonghucu, Upacara Perayaan Dewi Kwan Im

\section{Pendahuluan}

Berdasarkan Portal Informasi Indonesia (2013) Indonesia merupakan negara kesatuan yang memiliki kepulauan terbesar di dunia serta terletak di Asia Tenggara mempunyai 17.508 pulau dan terbentang di garis khatulistiwa. Indonesia diapit oleh benua Asia dan benua Australia, serta Samudra Hindia dan Samudra Pasifik. Menurut Kaelan, Indonesia merupakan negara yang memiliki banyak ragam di dalamnya, sebab terdiri dari 700 bahasa dan 200 suku. Oleh karena itu, Indonesia memiliki semboyan bhinneka tunggal ika (Kaelan, 2014).

Berdasarkan data dari Worldometer (2020) populasi penduduk Indonesia pada tahun 2020 adalah 273.523.615 jiwa. Menurut data resmi dari Portal Informasi Indonesia (2013) terdapat enam jenis agama yang diakui di Indonesia yaitu: Islam, Protestan, Katolik, Hindu, Buddha dan Khonghucu. Persentase umat Khonghucu di Indonesia sebesar 0,05\%. Etnis Cina masuk ke daerah Palembang menurut Retno Purwanti dalam Eva Febrian dan Farida Yunani Hasan pada zaman kerajaan Sriwijaya. Mereka mulai menetap di Palembang pada pertengahan abad ke-16, yaitu saat berdirinya kerajaan Islam di Palembang. Di Palembang, etnis Cina mulai membangun rumah sendiri berupa rumah rakit dan tempat ibadah berupa kelenteng (Febrian dan Hasan, 2015).

Menurut data Badan Pusat Statistik (2010) jumlah penduduk Palembang yang menganut agama Khonghucu ada 533 populasi jiwa. Agama Khonghucu menurut Mulyadi Liang sama seperti agama yang lainnya yaitu menganggap Tuhan Yang Maha Esa sebagai sang pencipta dunia. Namun agama Khonghucu memanggil Tuhan dengan sebutan Tian. Selain itu dalam agama Khonghucu dikenal para nabi yang berfungsi sebagai perantara dalam menyampaikan pesan-pesan dari Tian kepada umat Khonghucu melalui bimbingan agama yang disebut Jiao. Setiap upacara keagamaan mengandung empat aspek penting di dalamnya yaitu: tempat upacara, kegiatan upacara, benda-benda yang digunakan selama kegiatan upacara berlangsung, dan para pemimpin dan peserta upacara. Keempat aspek tersebut memiliki makna yang berbeda dalam setiap agama (Liang, 2015).

Dalam agama Khonghucu dikenal upacara yang dilaksanakan oleh umat Khonghucu yaitu upacara perayaan Dewi Kwan Im. Dewi Kwan Im menurut Siti Asiyah merupakan dewi welas asih karena memiliki hati yang lembut dan baik. Upacara perayaan Dewi Kwan Im dibagi menjadi tiga hari, yaitu: tanggal 19 bulan dua kalender Cina, tanggal 19 bulan enam kalender Cina, dan tanggal 19 bulan sembilan kalender Cina. Ketiga hari tersebut memiliki makna yang berbeda-beda. Pada tanggal 19 bulan dua kalender Cina merupakan hari kelahiran Dewi Kwan Im. Kemudian tanggal 19 bulan enam kalender Cina merupakan hari Dewi Kwan Im mencapai kesempurnaanNya. Sedangkan tanggal 19 bulan sembilan kalender Cina merupakan hari Dewi Kwan Im meninggalkan duniawi (Asiyah, 2014).

Dalam merayakan upacara perayaan Dewi Kwan Im, terdapat banyak tradisi yang berbeda-beda dilakukan oleh setiap umat Khonghucu di setiap daerah. Salah 
satunya di Kelenteng Dewi Kwan Im Palembang. Kelenteng ini memiliki tradisinya sendiri dalam melaksanakan upacara perayaan Dewi Kwan Im.

Penulis tertarik meneliti upacara perayaan Dewi Kwan Im yang dilaksanakan di Kelenteng Dewi Kwan Im Palembang karena penulis ingin mengkaji makna yang terdapat di dalam upacara tersebut. Penulis juga ingin melihat tradisi upacara perayaan Dewi Kwan Im yang dilaksanakan oleh masyarakat Khonghucu di Kelenteng Dewi Kwan Im Palembang. Alasan lainnya adalah karena penelitian mengenai makna upacara perayaan Dewi Kwan Im belum pernah ada yang meneliti sebelumnya.

\section{Metode Penelitian}

Pada penelitian ini, penulis menggunakan pendekatan penelitian kualitatif dengan metode penelitian studi kasus. Menurut Albi Anggito dan Johan Setiawan, penelitian kualitatif merupakan penelitian yang berdasarkan fenomena-fenomena yang terjadi dan menggunakan berbagai macam metode yang ada, serta bersifat deskriptif (Anggito dan Setiawan, 2018). Penulis menggunakan pendekatan penelitian kualitatif sebab penelitian tersebut sesuai dengan tujuan penelitian penulis, yaitu ingin mengetahui makna dari upacara perayaan Dewi Kwan Im yang dilaksanakan di Kelenteng Dewi Kwan Im Palembang. Kemudian menurut Mudjia Rahardjo, studi kasus merupakan bentuk penelitian yang dilakukan secara mendalam dan terperinci mengenai suatu peristiwa yang terjadi (Rahardjo, 2017). Penulis menggunakan pendekatan penelitian kualitatif dengan metode penelitian studi kasus sebab penulis ingin mengkaji secara mendalam mengenai proses upacara perayaan Dewi Kwan Im yang dilaksanakan oleh umat Khonghucu di Kelenteng Dewi Kwan Im Palembang dan makna dari upacara perayaan tersebut.

Penulis melaksanakan penelitian di Kelenteng Dewi Kwan Im yang berlokasi di KM 12 Palembang. Waktu penelitian yang digunakan penulis mulai dari bulan September 2020 hingga November 2020. Periode waktu mencakup pengumpulan data-data dengan melakukan observasi langsung ke lapangan, wawancara dengan narasumber, dan meliput kegiatan upacara perayaan Dewi Kwan Im. Menurut Suharsimi Arikunto, subjek penelitian merupakan individu, benda, dan hal mengenai variabel penelitian yang diteliti (Arikunto, 2016). Pada penelitian ini, subjek penelitian penulis yaitu umat Khonghucu di Kelenteng Dewi Kwan Im Palembang. Kemudian Karina Anggiani mendefinisikan objek penelitian sebagai suatu hal yang menjadi fokus dari penelitian yang dilakukan. Objek tersebut kemudian dikaji lebih dalam dengan menggunakan teori-teori yang berkaitan dengan objek penelitian tersebut (Anggiani, 2015). Pada penelitian ini, objek penelitian penulis yaitu upacara perayaan Dewi Kwan Im.

Pada penelitian ini, penulis memperoleh data yang dibutuhkan dengan wawancara, observasi, dan studi kepustakaan. Menurut Fandi Rosi Sarwo Edi, wawancara merupakan metode yang digunakan untuk mengumpulkan data atau informasi yang diinginkan (Edi, 2016). Pada penelitian ini, penulis akan melakukan wawancara dengan key informan dan informan yang memiliki kaitan dengan penelitian. Key informan yang akan diwawancarai oleh penulis yaitu Sakim selaku ketua Majelis Tinggi Agama Khonghucu Sumatera Selatan dan Lie Supriyadi selaku Rohaniawan Agama Khonghucu. Sedangkan informan yang akan diwawancarai oleh penulis yaitu Alam selaku ketua Kelenteng Dewi Kwan Im Palembang dan umat Khonghucu di Kelenteng Dewi Kwan Im Palembang. Serta Kurnia Setiawan selaku 
justifikator. Menurut Sukandarrumidi dalam Harry Prasetya, observasi merupakan pengamatan yang dilakukan secara langsung terhadap suatu objek mengenai fenomena yang sedang terjadi (Prasetya, 2017). Pada penelitian ini, penulis melakukan observasi secara langsung di Kelenteng Dewi Kwan Im Palembang untuk melihat proses upacara perayaan Dewi Kwan Im yang dilaksanakan oleh umat Khonghucu di Palembang. Menurut Syaibani dalam Ainul Azizah, studi kepustakaan merupakan informasi yang didapatkan melalui buku-buku ilmiah, laporan penelitian, dan sumber-sumber tertulis lainnya (Azizah, 2017). Pada penelitian ini, penulis menggunakan buku-buku, jurnal-jurnal, dan sumber resmi yang berkaitan dengan masalah penelitian penulis dan teori-teori penelitian agar memperkaya penelitian penulis.

Jenis sumber data yang digunakan oleh penulis berupa data primer dan data sekunder. Menurut Kuncoro dalam Edy Suandi dan Sri Susilo, data primer merupakan data yang diperoleh dari sumber asli, seperti: hasil wawancara dan observasi langsung ke lapangan (Suandi dan Susilo, 2011). Pada penelitian ini, data primer penulis diperoleh dari hasil wawancara dan observasi langsung mengenai upacara perayaan Dewi Kwan Im yang dilaksanakan di Kelenteng Dewi Kwan Im Palembang. Selain itu menurut Hanke dan Reitsch dalam Edy Suandi dan Sri Susilo, data sekunder merupakan data yang telah dikumpulkan oleh lembaga pengumpul data dan dipublikasikan kepada pembaca (Suandi dan Susilo, 2011). Pada penelitian ini, data sekunder penulis berupa buku, jurnal, dan situs resmi di internet yang berkaitan dengan penelitian penulis.

Menurut Mamik, pengolahan data berarti menyusun dan mengklarifikasi informasi-informasi yang telah didapat berdasarkan topik dari penelitian yang dilakukan (Mamik, 2015). Pada penelitian ini, penulis mengelolah data melalui hasil wawancara dan observasi yang dilakukan oleh penulis, kemudian hasil wawancara dan observasi tersebut akan dianalisis oleh penulis menggunakan analisis semiotika Charles Sanders Peirce untuk mengetahui makna yang terkandung dalam upacara perayaan Dewi Kwan Im. Penulis mengukur keabsahan data dengan menggunakan teknik triangulasi. Menurut Bachtiar S. Bachri, triangulasi merupakan teknik pemeriksaan data dengan menggunakan sesuatu yang berasal dari luar data tersebut untuk dijadikan perbandingan (Bachri, 2010).

\section{Hasil Temuan dan Diskusi}

Penulis menuangkan informasi yang telah didapatkan melalui kegiatan wawancara dan observasi di lapangan menggunakan teori semiotika Charles Sanders Peirce dengan konsep segitiga makna yang terdiri dari tanda, objek, dan interpretasi. Menurut Sakim, Dewi Kwan Im dulunya merupakan seorang manusia yang mendedikasikan kehidupannya demi kebahagiaan makhluk hidup di muka bumi. Jika ada manusia yang butuh pertolongan maka dengan memohon dengan tulus dan percaya dengan Dewi Kwan Im maka dipercaya Dewi tersebut akan menolong orang itu sebab Dewi Kwan Im merupakan sosok dewi welas asih (wawancara dengan Sakim di Kelenteng Thien Yong Keng Palembang pada tanggal 21 Oktober 2020 pukul 19.30 WIB). Pada penelitian ini penulis hanya meneliti upacara perayaan hari Dewi Kwan Im meninggalkan dunia. Sebab ketika upacara perayaan hari Dewi Kwan Im lahir dan hari Dewi Kwan Im mencapai kesempurnaan telah dilaksanakan penulis belum mengambil mata kuliah skripsi. Sehingga penulis hanya akan meneliti upacara perayaan Dewi Kwan Im terakhir yaitu pada saat Dewi Kwan Im 
meninggalkan dunia yang jatuh pada tanggal 4 November 2020 atau tanggal 19 bulan sembilan kalender Cina. Terdapat serangkaian prosesi urutan upacara perayaan Dewi Kwan Im yang dilaksanakan di Kelenteng Dewi Kwan Im Palembang yaitu upacara awal, inti, dan akhir.

Upacara awal diawali dengan doa pembuka yang dipimpin oleh Jason Gunawan selaku Sekretaris Majelis Tinggi Agama Khonghucu Indonesia Sumatera Selatan yang dilaksanakan pada pukul 10.00 WIB di Kelenteng Dewi Kwan Im Palembang. Bila dilihat dari semiotika maka tanda yang dihasilkan adalah Jason Gunawan selaku pemimpin doa membaca surat doa yang berisikan permohonan di dalamnya dan umat Khonghucu juga ikut serta memanjatkan doa. Lalu objeknya berupa umat Khonghucu yang ketika berdoa mengatupkan kedua tangan kemudian diletakkan di atas ulu hati dengan mata yang dipejamkan. Interpretasi yang dihasilkan dari tanda berupa doa pembuka yang dilakukan memiliki makna agar umat Khonghucu tidak lupa untuk senantiasa bersyukur dan berterima kasih kepada Tian karena atas berkatNya maka umat Khonghucu diberi kesempatan untuk berkumpul disini dan dapat merayakan upacara Dewi Kwan Im secara bersama-sama (wawancara dengan Alam di Kelenteng Dewi Kwan Im Palembang pada tanggal 4 November 2020 pukul 12.10 WIB).

Setelah melaksanakan doa pembuka Jason Gunawan didampingi Sakim selaku ketua Majelis Tinggi Agama Khonghucu Indonesia Sumatera Selatan membakar surat doa yang tadi dibacakan di depan arca Dewi Kwan Im. Prosesi kegiatan dari doa pembuka hingga membakar surat doa atau su wen berlangsung selama 20 menit. Tanda yang dihasilkan berupa Jason Gunawan membakar surat doa atau su wen yang berisikan permohonan di dalamnya. Objeknya berupa surat doa atau su wen dibakar di depan arca Dewi Kwan Im. Interpretasi yang dihasilkan dari tanda adalah agar surat doa yang berisikan permohonan tersebut dikirim ke langit dan dikabulkan oleh Tian (wawancara dengan Alam di Kelenteng Dewi Kwan Im Palembang pada tanggal 4 November 2020 pukul 12.10 WIB). Surat doa yang dibakar atau su wen memiliki makna sebagai penyempurnaan setelah melakukan doa bersama-sama. Pembakaran surat doa ini telah dilakukan sejak zaman Nabi Kongzi dan merupakan tradisi dari agama Khonghucu secara turun menurun (wawancara dengan Sakim di Kelenteng Thien Yong Keng Palembang pada tanggal 21 Oktober 2020 pukul 19.30 WIB).

Kemudian prosesi kegiatan berikutnya yaitu umat Khonghucu menyiapkan persembahan kepada Dewi Kwan Im. Tanda yang dihasilkan berupa umat Khonghucu menyiapkan persembahan kepada Dewi Kwan Im di altar sembahyang Dewi Kwan Im. Objeknya berupa persembahan yang diberikan kepada Dewi Kwan Im berupa buah-buahan, bunga, kue, dan air. Interpretasi yang dihasilkan dari tanda yaitu persembahan yang diberikan kepada Dewi Kwan Im sebagai bentuk rasa hormat umat Khonghucu kepada Dewi Kwan Im. Setiap persembahan tersebut memiliki makna masing-masing. Buah memiliki makna penuh cinta kasih dan kebajikan karena buah terkenal dengan ciri khasnya yaitu manis. Bunga memiliki makna keindahan karena Dewi Kwan Im merupakan sosok perempuan maka Ia menyukai bunga yang memiliki makna keindahan. Air memiliki makna sebagai sumber utama dalam kehidupan sebab semua makhluk di dunia pasti akan memerlukan air dalam kehidupannya sehari-hari. Sedangkan kue memiliki makna kebahagiaan dan dalam hidup tentunya manusia perlu berkembang (wawancara dengan Lie Supriyadi via WhatsApp pada tanggal 25 Oktober 2020 pukul 19.28 WIB). 
Untuk mengawali upacara inti perayaan Dewi Kwan Im umat Khonghucu di Kelenteng Dewi Kwan Im Palembang membakar hio untuk melakukan doa terlebih dahulu kepada Tian dan para Shen Ming. Tanda yang dihasilkan berupa umat Khonghucu membakar hio di depan altar sembahyang para Shen Ming di Kelenteng Dewi Kwan Im Palembang. Objeknya berupa hio dibakar dengan menggunakan lilinlilin yang ada di altar sembahyang. Interpretasi yang dihasilkan dari tanda berupa hio sebagai media perantara komunikasi antara umat Khonghucu dengan Tian dan para Shen Ming. Oleh karena itu umat Khonghucu dalam melaksanakan sembahyang menggunakan hio.

Setelah membakar hio umat Khonghucu secara individual melakukan doa kepada Tian dan para Shen Ming. Menurut umat Khonghucu di Kelenteng Dewi Kwan Im Palembang dalam melaksanakan doa harus berurutan dimulai untuk Tian terlebih dahulu dan kemudian para Shen Ming (wawancara dengan Andi Saputra di Kelenteng Dewi Kwan Im Palembang pada tanggal 4 November 2020 pukul 15.10 WIB). Tanda yang dihasilkan berupa umat Khonghucu melakukan doa kepada Tian dan para Shen Ming di Kelenteng Dewi Kwan Im Palembang. Objeknya berupa umat Khonghucu ketika melakukan doa menggunakan hio sebagai media perantara komunikasi dengan Tian dan para Shen Ming. Interpretasi yang dihasilkan dari tanda yaitu umat Khonghucu secara individu melakukan doa kepada Tian dan para Shen Ming sebagai bentuk hormat, rasa syukur, dan terima kasih atas berkat dan perlindungan yang diberikan hingga saat ini.

Kemudian pukul 13.00 WIB Kelenteng Dewi Kwan Im mengadakan ritual Kokhun dan berlangsung selama satu jam. Tanda yang dihasilkan berupa umat Khonghucu yang memiliki indra ke-enam melakukan $K i$ Tong dengan menancapkan pisau ke mulutnya dan mengibarkan bendera yang bertuliskan nama Kelenteng Dewi Kwan Im dan nama para prajurit Shen Ming. Objeknya berupa umat Khonghucu yang melakukan Ki Tong memakai tiao to atau baju khusus saat melaksanakan ritual Kokhun. Interpretasi yang dihasilkan dari tanda yaitu umat Khonghucu dapat melakukan komunikasi secara langsung dengan dewa melalui perantara Ki Tong. Oleh karena itu umat Khonghucu percaya bahwa Dewi Kwan Im dan para prajurit Shen Ming turut hadir dalam upacara perayaan tersebut melalui bantuan informasi dari komunikasi langsung dengan dewa melalui $\mathrm{Ki}$ Tong. Sehingga ritual Kokhun sangat berharga bagi umat Khonghucu di Kelenteng Dewi Kwan Im Palembang untuk mengungkapkan rasa syukur dan hormat secara langsung kepada Dewi Kwan Im dan para Shen Ming lainnya (wawancara dengan Andi Saputra di Kelenteng Dewi Kwan Im Palembang pada tanggal 4 November 2020 pukul 15.10 WIB). Tiao to merupakan simbolis dari baju keagungan dewa atau Shen Ming. Pada baju tiao to ditulis nama kelenteng dan nama dewa. Hal tersebut bertujuan sebagai media untuk memanggil para dewa dan umat Khonghucu mempercayai bahwa dengan menuliskan nama dewa maka dewa tersebut akan masuk ke dalam tubuh umat Khonghucu yang memiliki indra ke-enam. Untuk warna baju pada tiao to disesuaikan dengan kearifan lokal. Warna baju tiao to yang digunakan di Kelenteng Dewi Kwan Im Palembang yaitu bewarna merah dan emas. Memiliki makna sebagai keagungan bagi para dewa atau Shen Ming (wawancara dengan Alam di Kelenteng Dewi Kwan Im Palembang pada tanggal 4 November 2020 pukul $12.10 \mathrm{WIB}$ ).

Atraksi barongsai sebagai bagian dari upacara ritual Kokhun. Tanda yang dihasilkan berupa atraksi barongsai yang dilaksanakan di Kelenteng Dewi Kwan Im Palembang. Objeknya berupa upacara perayaan Dewi Kwan Im. Interpretasi yang dihasilkan dari tanda tersebut yaitu adanya atraksi barongsai dalam upacara perayaan 
Dewi Kwan Im memiliki makna untuk menghalangi roh-roh jahat yang ingin masuk ke dalam Kelenteng Dewi Kwan Im Palembang atau yang ingin mengganggu prosesi pelaksanaan upacara perayaan Dewi Kwan Im (wawancara dengan Alam di Kelenteng Dewi Kwan Im Palembang pada tanggal 4 November 2020 pukul 12.10 WIB).

Upacara akhir ditandai dengan umat Khonghucu membakar Kim Cua di halaman luar Kelenteng Dewi Kwan Im Palembang. Objeknya berupa kertas Kim Cua berwarna emas dibakar. Interpretasi yang dihasilkan dari tanda yaitu sebagai bentuk persembahan terakhir yang diberikan oleh umat Khonghucu di Kelenteng Dewi Kwan Im Palembang kepada Dewi Kwan Im sebelum prosesi upacara perayaan Dewi Kwan Im berakhir.

Selain upacara awal, inti dan penutup yang dilaksanakan oleh Kelenteng Dewi Kwan Im Palembang, terdapat tradisi yang hanya terdapat di Kelenteng Dewi Kwan Im Palembang saja. Tradisi tersebut berupa pemberkatan atau blessing. Kegiatan pemberkatan ini dilaksanakan setelah prosesi kegiatan upacara perayaan Dewi Kwan Im dilaksanakan. Tujuannya agar umat Khonghucu yang telah mengikuti serangkaian kegiatan prosesi upacara perayaan Dewi Kwan Im di Kelenteng Dewi Kwan Im Palembang mendapat berkat langsung dari Dewi Kwan Im. Terdapat tata cara dalam melakukan pemberkatan. Pertama Alam memegang bambu yang diarahkan ke dahi umat Khonghucu lalu diarahkan ke atas. Hal ini bertujuan agar segala penyakit atau beban pikiran di dalam tubuh umat Khonghucu dibuang. Pada saat Alam melakukan prosesi pemberkatan umat Khonghucu mengatupkan kedua tangannya sebagai bentuk hormat kepada Dewi Kwan Im. Setelah itu umat Khonghucu mengambil gelang yang telah disediakan oleh Kelenteng Dewi Kwan Im Palembang (wawancara dengan Alam di Kelenteng Dewi Kwan Im Palembang pada tanggal 4 November 2020 pukul 12.10 WIB).

Tanda yang dihasilkan berupa Alam melakukan proses pemberkatan kepada umat Khonghucu di Kelenteng Dewi Kwan Im Palembang. Objeknya yaitu umat Khonghucu mengatupkan kedua tangannya dan diletakkan di dada pada saat prosesi pemberkatan berlangsung. Interpretasi yang dihasilkan berupa umat Khonghucu mempercayai bahwa Dewi Kwan Im hadir di Kelenteng Dewi Kwan Im Palembang dan memberikan berkat langsung kepada umat Khonghucu di Kelenteng Dewi Kwan Im Palembang melalui perantara Alam. Menurut Alam pemberkatan yang dilakukannya mengandung tiga makna yaitu untuk kesehatan, keselamatan dan rejeki (wawancara dengan Alam di Kelenteng Dewi Kwan Im Palembang pada tanggal 4 November 2020 pukul 12.10 WIB).

Teori Semiotika menurut Charles Sanders Peirce dalam Triadi Syadian merupakan teori yang berkaitan dengan logika guna melihat kemampuan manusia dalam bernalar. Peirce membagi teori semiotika menjadi tiga konsep atau yang dikenal sebagai teori segitiga makna atau triangle meaning. Tiga konsep tersebut terdiri dari: tanda berupa wujud fisik yang dapat dilihat dan dirasakan secara langsung oleh panca indera manusia, objek berupa hal yang dirujuk oleh tanda, dan interpretasi merupakan persepsi manusia terhadap tanda (Syadian, 2015). Upacara perayaan Dewi Kwan Im yang dilaksanakan di Kelenteng Dewi Kwan Im Palembang memiliki makna sebagai bentuk penghormatan umat Khonghucu kepada Dewi Kwan Im atas berkat yang diberikan oleh Dewi Kwan Im, sehingga umat Khonghucu selalu melaksanakan perayaan pada hari besar Dewi Kwan Im yang diadakan di Kelenteng Dewi Kwan Im Palembang. Selain itu tradisi upacara perayaan Dewi Kwan Im yang 
dilaksanakan di Kelenteng Dewi Kwan Im Palembang sebagai bentuk kepercayaan umat Khonghucu kepada Dewi Kwan Im.

Komunikasi transendental menurut Deddy Mulyana dalam Farih Miftahul Huda merupakan komunikasi yang sangat penting bagi manusia karena terjadi komunikasi secara langsung antara Tuhan dengan manusia. Keberhasilan komunikasi ini tidak hanya berdampak pada kehidupan duniawi tetapi di dunia akhirat juga (Huda, 2019). Umat Khonghucu di Kelenteng Dewi Kwan Im dapat merasakan kehadiran Dewi Kwan Im secara langsung selama prosesi upacara perayaan dan pemberkatan dilaksanakan. Umat Khonghucu mempercayai bahwa Dewi Kwan Im hadir di tengah-tengah Kelenteng Dewi Kwan Im Palembang dan memberikan berkat kepada umat Khonghucu.

Asimilasi menurut Reni Juliani dan Hafied Cangara merupakan proses sosial ketika sekelompok masyarakat melakukan interaksi satu sama lain dengan latar belakang budaya berbeda dalam rentang waktu yang cukup lama, sehingga lambat laun akan terjadi pembauran budaya dan menimbulkan budaya baru (Juliani dan Cangara, 2015). Upacara perayaan Dewi Kwan Im yang dilaksanakan oleh Kelenteng Dewi Kwan Im Palembang bukan upacara perayaan asli masyarakat Tionghoa, namun merupakan upacara perayaan yang berasal dari budaya campuran umat Khonghucu di Kelenteng Dewi Kwan Im Palembang. Hal tersebut diperkuat oleh Alam yaitu upacara perayaan Dewi Kwan Im yang dilaksanakan oleh Kelenteng Dewi Kwan Im Palembang merupakan campuran dari budaya masyarakat Hokkien sehingga memiliki sedikit perubahan dalam melaksanakan perayaan hari besar Dewi Kwan Im (wawancara dengan Alam di Kelenteng Dewi Kwan Im Palembang pada tanggal 4 November 2020 pukul 12.10 WIB).

Selain itu menurut Sakim sikap toleransi sangat diperlukan dalam proses asimilasi budaya. Apabila umat Khonghucu menghormati setiap perbedaan budaya dan menerimanya dengan hati yang lapang maka tidak akan ada masalah. Sebab semua tradisi sembahyang yang dilakukan oleh umat Khonghucu diturunkan dari kakek nenek moyang sehingga generasi yang sekarang perlu meneruskan tradisi tersebut dan menerima jika ada budaya baru yang masuk selama tidak menyesatkan (wawancara dengan Sakim di Kelenteng Thien Yong Keng Palembang pada tanggal 21 Oktober 2020 pukul 19.30 WIB). Tradisi yang ada di Kelenteng Dewi Kwan Im Palembang merupakan ciri khas dari kelenteng tersebut dan menjadi daya tarik dari Kelenteng Dewi Kwan Im Palembang sebab tidak dapat ditemukan di kelenteng yang lain (wawancara dengan Kurnia Setiawan via WhatsApp pada tanggal 17 November 2020 pukul 13.00 WIB).

\section{Simpulan}

Makna upacara perayaan Dewi Kwan Im bagi umat Khonghucu yaitu sebagai bentuk rasa hormat dan terima kasih umat Khonghucu kepada Dewi Kwan Im sebab selama ini Dewi Kwan Im dipercaya telah banyak membantu dan menolong para umat Khonghucu yang membutuhkan bantuanNya. Pada saat hari besar seperti ini umat Khonghucu mengungkapkan rasa terima kasih melalui persembahanpersembahan terbaik yang diberikan kepada Dewi Kwan Im. Selain itu umat Khonghucu dapat melakukan komunikasi secara langsung dengan Dewi Kwan Im dan para Shen Ming melalui bantuan Ki Tong pada saat prosesi ritual Kokhun dilaksanakan. 
Tradisi upacara perayaan Dewi Kwan Im yang dilaksanakan oleh umat Khonghucu di Kelenteng Dewi Kwan Im Palembang merupakan tradisi budaya Hokkien. Selain itu di Kelenteng Dewi Kwan Im Palembang terdapat tradisi perayaan yang hanya terdapat di kelenteng tersebut yaitu prosesi pemberkatan atau blessing. Prosesi pemberkatan yang menjadi ciri khas tradisi Kelenteng Dewi Kwan Im Palembang ini dipercaya kuat oleh umat Khonghucu Kelenteng Dewi Kwan Im Palembang. Sebab umat Khonghucu mempercayai kehadiran Dewi Kwan Im dan memberkati umat Khonghucu secara langsung melalui perantara Alam.

\section{Ucapan Terima Kasih}

Penulis berterimakasih kepada dosen pembimbing, kepada lima narasumber yang telah memberikan informasi terkait penelitian penulis, keluarga, dan temanteman yang senantiasa mendukung penulis hingga dapat menyelesaikan penelitian ini.

\section{Daftar Pustaka}

Anggiani, Karina. (2015). Program Biomethagreen Sebagai Kegiatan Corporate Social Responsibility PT PLN (Persero) Distribusi Jawa Barat dan Banten. Skripsi. Bandung: Universitas Padjadjaran

Anggito, Albi dan Johan Setiawan. (2018). Metodologi Penelitian Kualitatif. Jawa Barat: CV Jejak

Arikunto, Suharsimi. (2016). Pengembangan Kompetensi dan Pendidikan Berkelanjutan Pustakawan PTAIN: Studi Kasus di Perpustakaan UIN Sunan Kalijaga Yogyakarta. Jurnal Pembangunan Pendidikan. 4(1). 1-14

Asiyah, Siti. (2014). Peran Tokoh Agama Dalam Membina Kerukunan Antar Umat Beragama di Kawasan Pecinan Kota Semarang. Skripsi. Semarang: IAIN Walisongo

Azizah, Ainul. (2017). Studi Kepustakaan Mengenai Landasan Teori dan Praktik Konseling Naratif. Jurnal BK Unesa. 7(2). 1-7

Bachri, Bachtiar S. (2010). Meyakinkan Validitas Data Melalui Triangulasi Pada Penelitian Kualitatif. Jurnal Teknologi Pendidikan. 10(1). 46-62

Badan Pusat Statistik. (2010). Penduduk Menurut Wilayah dan Agama yang Dianut. Diakses dari https://sp2010.bps.go.id/index.php/site/tabel/ pada tanggal 23 September 2020

Edi, Fandi Rosi Sarwo. (2016). Teori Wawancara Psikodiagnostik. Yogyakarta: PT Leutika Nouvalitera

Febrian, Eva dan Farida Yunani Hasan. (2015). Perkembangan Pemukiman Masyarakat Tionghoa di Palembang Pasca Kesultanan Palembang. Jurnal Criksetra. 4(7). 18-28

Huda, Farih Miftahul. (2019). Ziarah Sebagai Media Komunikasi Transendental (Studi Etnografi pada Para Peziarah di Pemakaman Syekh Makhdum Wali Karangwelas Banyumas). Skripsi. Purwokerto: IAIN Purwokerto

Juliani, Reni dan Hafied Cangara. (2015). Komunikasi AntarBudaya Etnis Aceh dan Bugis-Makassar Melalui Asimilasi Perkawinan di Kota Makassar. Jurnal Ilmu Komunikasi. 4(1). 70-87

Kaelan. (2014). Pendidikan Pancasila Edisi Reformasi 2014. Yogyakarta: Paradigma Liang, Mulyadi. (2015). Mengenal Agama Khonghucu. Depok: SPOC

Mamik. (2015). Metodologi Kualitatif. Sidoarjo: Zifatama Publisher 
Marianti, Dhea dan Suzy S. Azeharie. (2018). Komunikasi Transendental Antara Penari Tamborin dan Tuhan. Skripsi. Jakarta: Ilmu Komunikasi Universitas Tarumanagara

Portal Geografi Indonesia. (2013). Geografi Indonesia. Diakses dari http://www.indonesia.go.id/ pada tanggal 23 September 2020

Prasetya, Harry. (2017). Implementasi Pendidikan Karakter Demokratis dan Disiplin Dalam Pembelajaran Penjasorkes Pada Siswa di SD Negeri 1 Kemiri Boyolali. Skripsi. Surakarta: Universitas Muhammadiyah Surakarta

Rahardjo, Mudjia. (2017). Studi Kasus Dalam Penelitian Kualitatif: Konsep dan Prosedurnya. Skripsi. Malang: Universitas Islam Negeri Maulana Malik Ibrahim

Suandi, Edy dan Sri Susilo. (2011). Strategi Pengembangan Usaha Mikro Kecil dan Menengah di Provinsi Daerah Istimewa Yogyakarta. Jurnal Ekonomi Pembangunan. 12(1). 45-55

Syadian, Triadi. (2015). Analisis Semiotika Pada Film Laskar Pelangi. Jurnal Proporsi. 1(1). 51-63

Worldometer. (2020). Indonesia Population. Diakses dari https://www.worldometers.info/world-population/indonesia-population/ pada tanggal 23 September 2020 